\title{
Efeito do Residual de Atrazina e Atrazina + Simazina em Soja
}

\author{
Residual Effect of Atrazine and Atrazine + Simazine in Soybean \\ Felipe Tolloti Peruzzo, Diecson Ruy Orsolin da Silva, Álvaro André Alba da Silva*, Bruna Dal'Pizol \\ Novello, Marina Luiza Cuchi
}

Universidade Federal de Santa Maria, Frederico Westphalen, RS, Brasil. *Autor para correspondência: alvaroalba1@outlook.com.

Submissão: 10/04/2019 / Aceite: 10/12/2019

\begin{abstract}
RESUMO
A persistência no solo de herbicidas do grupo das triazinas é dependente de basicamente de condições de precipitação e características do solo. Objetivou-se avaliar o efeito residual de diferentes épocas de aplicação e doses de atrazina e atrazina + simazina para a cultura da soja. Conduziram-se experimentos a campo e casa de vegetação. A campo utilizou-se o delineamento de parcelas subdivididas com quatro repetições, sendo o fator A composto por épocas de aplicação 56, 49, 42, 35, 28, 21 e 14 dias antes da semeadura da soja; e fator $\mathrm{B}$, pelos herbicidas atrazina e atrazina + simazina. Para o experimento em casa de vegetação o delineamento inteiramente casualizados, o fator A foi constituído de doses 0,570 , $1.140,1.715,2.285,2.860,3.430$ e $4.000 \mathrm{~g}$ i.a.ha ${ }^{-1}$; e fator B pelos herbicidas atrazina e atrazina + simazina. A aplicação dos tratamentos foi realizada com pulverizador costal pressurizado por $\mathrm{CO}_{2}$, após a aplicação realizou-se a semeadura da soja. A campo avaliou-se o estande de plantas, fitotoxicidade, estatura, altura de inserção do primeiro entrenó, teor de clorofila e produtividade. Em casa de vegetação foram avaliados fitotoxicidade, estatura de plantas, área foliar e massa seca. Após os dados foram submetidos a análise de variância e quando significativas as medias foram comparadas pelo teste Tukey a $5 \%$. A simulação de residual dos herbicidas atrazina e atrazina + simazina no solo apresentam comportamento similares quanto aos efeitos na soja. No experimento a campo, devido às altas precipitações ocorridas no intervalo entre as aplicações dos herbicidas e a semeadura da soja, não foram observados efeitos fitotóxicos ou redução na produtividade da cultura. Em casa de vegetação, o aumento da dose residual dos herbicidas no solo incrementou os efeitos tóxicos na soja.
\end{abstract}

PALAVRAS-CHAVE: triazinas, condições ambientais, fitotoxicidade, Glycine max.

\begin{abstract}
The soil persistence of herbicides from the triazines group is basically dependent on precipitation conditions and soil characteristics. The objective of this study was to assess the residual effect of different application times and atrazine and atrazine + simazine doses for the soybean crop. Experiments were conducted in the field and greenhouse. In the field, the design of subdivided plots with four replications was used, with factor A composed of application times 56, 49, 42, 35, 28, 21, and 14 days before soybean sowing; and factor $\mathrm{B}$, by the herbicides atrazine and atrazine + simazine. For the greenhouse experiment, the design was completely randomized blocks, factor $A$ doses $0,570,1140,1715,2285,2860,3430$, and $4000 \mathrm{~g}$ i.a. ha $^{-1}$, factor $B$ herbicides atrazine and atrazine + simazine. The application of the treatments was carried out with a $\mathrm{CO}_{2}$ pressurized sprayer, after the application of the soybean. The field was assessed regarding the plant stand, phytotoxicity, stature, height of insertion of the first training, chlorophyll content, and $\mathrm{kg} \mathrm{ha}^{-1}$ yield. In the greenhouse, phytotoxicity, plant height, leaf area, and dry mass were assessed. Then, data were submitted to analysis of variance and, when significant, the means were compared by the Tukey test at $5 \%$. The residual simulation of the herbicides atrazine and atrazine + simazine in the soil showed similar behavior regarding the effects on soybean. In the field experiment, due to the high precipitations that occurred in the interval between herbicide applications and soybean sowing, no phytotoxic effects or reduction in crop yield were observed. In the greenhouse, increasing the residual dose of herbicides in the soil increased the toxic effects on soybean.
\end{abstract}

KEYWORDS: triazines, environmental conditions, phytotoxicity, Glycine max.

\section{INTRODUÇÃO}

Com o aumento da população mundial o setor agrícola cada vez mais vem ganhando ênfase, onde uma das 
maiores demandas de mercado é o constante aumento da produção, fator este que se dá pela intensificação do uso do solo, abertura de novas fronteiras agrícolas e a adoção de novas tecnologias visando o aumento da produção (MANCUSO et al. 2011).

A cultura do milho pode ser semeada de julho a dezembro no Sul do Brasil, especialmente na região norte do Rio Grande do Sul, semeaduras antecipadas de milho vem ganhando espaço, onde produtores utilizam essa técnica visando a implantação de uma segunda safra. Porém a ocorrência de geadas tardia compromete significativamente o desenvolvimento do milho, fazendo com que o produtor opte pela interrupção da cultura e realize o cultivo da soja em sucessão. Semeadura que em suma maioria é realizada em áreas pulverizadas com herbicidas seletivos à cultura do milho, como é o caso do grupo químico das triazinas, onde podem apresentar efeitos de carryover sobre a soja.

O método de controle químico tornou-se uma prática indispensável para a agricultura em larga escala, por sua menor dependência de mão de obra, eficiência e rapidez no manejo das plantas daninhas se considerado a outros métodos de controle (SANTOS et al. 2013).

Inúmeros são os herbicidas que possuem longo efeito residual no solo, dentre estes destaca-se a atrazina, herbicida pertencente ao grupo químico das triazinas, tendo como mecanismo de ação a inibição do fotossistema II, os quais são utilizados para o controle seletivo em pré e pós-emergência das plantas daninhas mono e dicotiledôneas na cultura do milho.

Logo, um dos grandes problemas constatados nos diversos cultivos tem sido o efeito carryover de herbicidas, visto a atividade residual que pode comprometer a produtividade dos cultivos em sucessão ou rotação (MANCUSO et al. 2011). O movimento dos herbicidas do grupo das triazinas no solo é classificado como baixo a moderado, embora possa variar de acordo com o composto, condições climáticas e características de solo (OLIVEIRA JR et al. 2011).

O parâmetro utilizado para estimar a persistência do produto no solo é a meia-vida que, segundo INOUE et al. (2003), é em média de 60 dias para atrazina e 22 dias para simazina. Mas como as culturas respondem de forma diferente quanto à sensibilidade aos herbicidas, é importante a realização de trabalhos que analisem as diferentes situações encontradas. Por essas razões, informações obtidas em determinados locais, quando extrapoladas para outras regiões, de solo e clima diferentes, apresentam sempre valor relativo.

Assim o objetivo do trabalho foi avaliar o efeito residual de diferentes épocas de aplicação e doses de atrazina e a mistura formulada de atrazina + simazina na cultura da soja.

\section{MATERIAL E MÉTODOS}

Foram conduzidos dois experimentos sendo um a campo na safra 2017/18 e o outro em casa de vegetação em 2018. O solo utilizado em ambos experimentos foi classificado como Latossolo Vermelho Alumino férrico típico (EMBRAPA 2013), com as seguintes características físico-químicas: Argila $=60 \%, \mathrm{pH}$ 6,2 , Índice SMP $=6,2, \mathrm{P}=4,5 \mathrm{mg} \mathrm{dm}^{-3}, \mathrm{~K}=120,5 \mathrm{mg} \mathrm{dm}^{-3}, \mathrm{M} . \mathrm{O}=3,2 \%, \mathrm{Al}=0 \mathrm{cmol} \mathrm{dm}^{-3}, \mathrm{Ca}=8,7 \mathrm{cmol}$ $\mathrm{dm}, \mathrm{Mg}=4,6 \mathrm{cmol} \mathrm{dm}^{-3}, \mathrm{CTC}=16,6 \mathrm{cmol} \mathrm{dm}^{-3}, \mathrm{H}+\mathrm{Al}=3,0 \mathrm{cmol} \mathrm{dm}^{-3}$, Saturação de Base (SMP) $=81,9$ $\mathrm{cmol} \mathrm{dm}{ }^{-3}, \mathrm{~S}=10,5 \mathrm{mg} \mathrm{dm}^{-3}, \mathrm{Zn}=5,7 \mathrm{mg} \mathrm{dm}^{-3}, \mathrm{Cu}=11,2 \mathrm{mg} \mathrm{dm}^{-3}, \mathrm{~B}=0,4 \mathrm{mg} \mathrm{dm}^{-3}, \mathrm{Mn}=5,0=\mathrm{mg} \mathrm{dm}^{-3}$.

\section{Experimento a Campo}

$O$ experimento foi conduzido em delineamento de parcelas subdivididas com quatro repetições, em esquema fatorial $(2 \times 7)+1$, sendo que o fator $A$ foi composto pelos herbicidas, atrazina (Gesaprim SC ${ }^{\circledR}$, 2000 g i.a. $L^{-1}$ ), e atrazina + simazina (Primatop $S C^{\circledR}, 1000+1000$ g i.a. $L^{-1}$ ) e, fator $B$ composto pelas épocas de aplicação de herbicidas antes da semeadura (DAS) da soja: 56, 49, 42, 35, 28, 21 e 14 DAS, e uma testemunha sem aplicação. As unidades experimentais foram compostas por parcelas contendo cinco linhas de semeadura espaçadas $0,45 \mathrm{~m}$ por $4 \mathrm{~m}$ de comprimento. Para aplicação dos tratamentos utilizou-se pulverizador costal pressurizado por $\mathrm{CO}_{2}$, com pressão constante de $0,8 \mathrm{Kgf} \mathrm{cm}^{-2}$, equipado com barra de quatro pontas XR11002 espaçados $0,5 \mathrm{~m}$ entre si, e volume de calda de $150 \mathrm{~L} \mathrm{ha}^{-1}$. As datas e condições meteorológicas no momento das aplicações e durante o experimento estão descritas na Tabela 1 e Figura 1.

Após a aplicação dos tratamentos realizou-se a semeadura da soja, no dia 01 de novembro de 2017, cultivar BMX Lança IPRO estabelecendo população de 233 mil plantas ha ${ }^{-1}$, adubação de $350 \mathrm{Kg} \mathrm{ha}^{-1}$ de adubo NPK 05-30-15. Os tratos culturais foram realizados conforme a necessidade da cultura.

As variáveis avaliadas foram o estande de plantas de soja aos 15 dias após o início da emergência, no qual foram contadas em $2 \mathrm{~m}$ lineares da linha central de semeadura; estatura e fitotoxicidade aos 15, 30 e 45 dias após a emergência da soja (DAE), na qual foram atribuídas notas que variaram de 0 a 100, as quais correspondem a nenhum efeito fitotóxico e morte das plantas, respectivamente (SBCPD 1995); teor 
de clorofila aos 30 DAE em cinco plantas por parcela, com auxílio do equipamento (Clorofilog CFL 1030 ${ }^{\circledR}$, FALKER), as leituras foram realizadas no folíolo da última folha totalmente expandida, evitando-se as nervuras principais do folíolo; índice de cobertura vegetal com o auxílio do aplicativo para smartphone Canapeo, expresso em percentagem de cobertura, e ao final foi determinado a produtividade de grãos (kg $\mathrm{ha}^{-1}$ ) colhendo as três linha centrais.

Tabela 1. Épocas de aplicação e condições meteorológicas no momento da aplicação.

Table 1. Application times and weather conditions at the time of application.

\begin{tabular}{cccccc}
\hline $\begin{array}{c}\text { Época de } \\
\text { aplicação }\end{array}$ & Data & Horário de início & $\begin{array}{c}\text { Temperatura } \\
\left({ }^{\circ} \mathrm{C}\right)\end{array}$ & $\begin{array}{c}\text { Umidade relativa } \\
(\text { UR\%) }\end{array}$ & $\begin{array}{c}\text { Precipitação } \\
\text { acumulada }(\mathrm{mm})\end{array}$ \\
\hline 56 DAS & $05 / \mathrm{set}$ & $15: 05$ & 20,0 & 93,0 & 0,00 \\
49 DAS & $14 / \mathrm{set}$ & $13: 40$ & 40,0 & 35,0 & 21,4 \\
42 DAS & $21 / \mathrm{set}$ & $16: 40$ & 30,0 & 36,0 & 64,0 \\
35 DAS & $27 / \mathrm{set}$ & $17: 00$ & 24,0 & 58,0 & 68,6 \\
28 DAS & $04 /$ out & $17: 35$ & 24,3 & 34,0 & 148,2 \\
21 DAS & $11 /$ out & $07: 50$ & 20,7 & 83,0 & 210,2 \\
14 DAS & $18 /$ out & $07: 55$ & 22,7 & 71,0 & 243,8 \\
Semeadura & $01 /$ nov & - & - & - & 490,0 \\
\hline
\end{tabular}

DAS: Dias antes da semeadura.

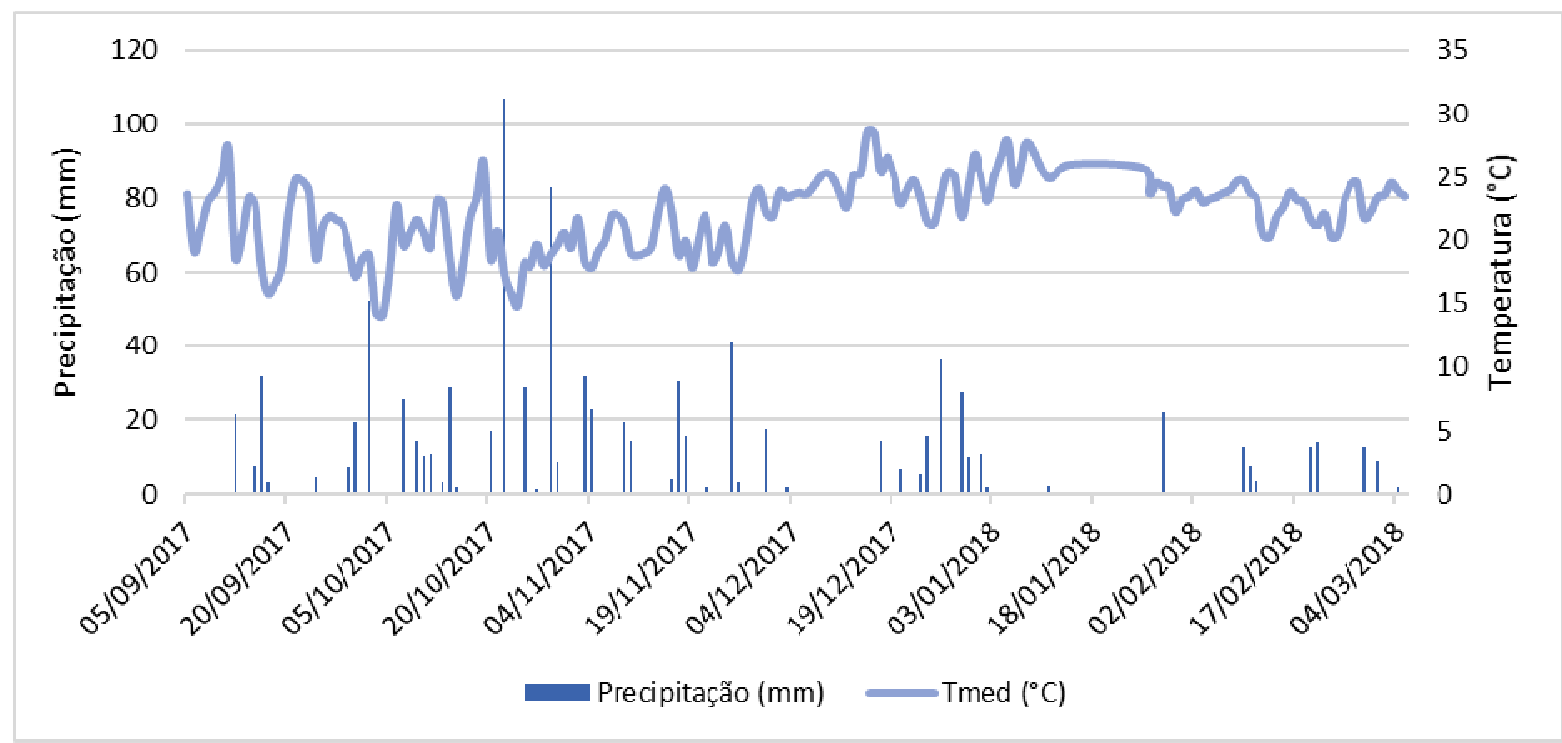

Fonte: Adaptado INMET 2017/18.

Figura 1. Dados meteorológicos (precipitação e temperatura média) no período de condução do experimento a campo.

Figure 1. Meteorological data (rainfall and mean temperature) in the period of the field experiment.

\section{Experimento em Casa de Vegetação}

As unidades experimentais foram constituídas por vasos de oito litros de capacidade, com diâmetro de $23 \mathrm{~cm}$, preenchidos com solo. O delineamento experimental utilizado foi inteiramente casualizados (DIC), com quatro repetições em esquema fatorial $(2 \times 7)+1$, sendo que o fator $A$ composto por herbicidas atrazina (Gesaprim SC ${ }^{\circledR}, 2000$ g i.a. $L^{-1}$ ), e atrazina + simazina (Primatop SC ${ }^{\circledR}, 1000+1000$ g i.a. L $^{-1}$ ); fator B foi composto por doses dos herbicidas: 0, 570, 1.140, 1.715, 2.285, 2.860, 3.430 e $4.000 \mathrm{~g}^{\text {i.a. }}$ ha $^{-1}$. Dois dias antes da aplicação dos tratamentos os vasos foram saturados com água, após atingirem a capacidade de campo realizou-se a aplicação dos tratamentos, onde, as doses foram realizadas de forma semelhante ao experimento a campo. Após a aplicação realizou-se a semeadura da soja (BMX Lança IPRO) na densidade de seis sementes por vaso, após a emergência estabelecendo três plantas por vaso. A irrigação por sua vez ocorreu de forma diária, sendo irrigado $5 \mathrm{~mm} \mathrm{dia}^{-1}$.

Foram avaliadas a fitotoxicidade utilizando escala visual aplicando-se notas de 0 a 100 , onde 0 
representa ausência de fitotoxicidade e 100 representa a morte da planta (SBCPD 1995), e estatura de plantas 7, 14, 21 e 28 dias após a emergência (DAE) e diâmetro de caule aos 28 DAE. Ao final do experimento foi determinada área foliar das plantas, destacando-se o pecíolo das folhas, os quais foram digitalizadas em scanner e avaliadas no software Imagem $J^{\circledR}$. Após a secagem das plantas estufa de secagem com circulação de ar forçada, à temperatura de $60 \stackrel{\circ}{\circ}$ por 72 horas, e posterior determinação da matéria seca das plantas.

Posteriormente a obtenção dos dados, os mesmos foram submetidos a análise de variância, pelo teste $F(p<0,05)$, quando significativas, as médias dos tratamentos de herbicidas foram comparadas pelo teste Tukey a $5 \%$ de probabilidade de erro, enquanto que para as épocas de aplicação e doses dos herbicidas foram testados equações de modelos lineares e não lineares.

\section{RESULTADOS E DISCUSSÃO}

\section{Experimento a campo}

Não foi verificado interação entre herbicidas e épocas de aplicação para nenhuma das variáveis avaliadas, no entanto foram verificados efeitos simples para o fator herbicidas para as variáveis estatura aos 15 e 30 DAE e efeito simples do fator épocas de aplicação dos herbicidas para as variáveis e estatura aos 30 DAE e produtividade da soja, não ocorreram efeitos para a variável fitotoxicidade (Tabela 2).

Tabela 2. Análise da variância (teste F) para as variáveis da soja em função da aplicação de atrazine e atrazina + simazina em diferentes épocas antes da semeadura da soja.

Table 2. Analysis of the variance (test F) for the soybean variables as a function of the application of atrazine and atrazine + simazine at different times before soybean sowing.

\begin{tabular}{lcccc}
\hline \multicolumn{1}{c}{ Variáveis } & Herbicida & Época & Herbicida X Época & CV (\%) \\
\hline Estande de plantas 15 DAE & 0,518 & 0,644 & 0,452 & 9,4 \\
Estatura 15 DAE & 0,029 & $<0,001$ & 0,502 & 4,5 \\
Estatura 30 DAE & $<0,001$ & $<0,001$ & 0,100 & 2,6 \\
Estatura 45 DAE & 0,162 & 0,186 & 0,416 & 7,0 \\
Fitotoxicidade 15 DAE & - & - & - & - \\
Fitotoxicidade 30 DAE & - & - & - & - \\
Fitotoxicidade 45 DAE & - & - & - & - \\
ICV 30 DAE & 0,0775 & 0,172 & 0,962 & 7,5 \\
Clorofila Total & 0,849 & 0,276 & 0,746 & 5,3 \\
Clorofila A & 0,076 & 0,506 & 0,946 & 6,2 \\
Clorofila B & 0,867 & 0,274 & 0,915 & 4,81 \\
№ Vagens & 0,263 & 0,169 & 0,320 & 7,1 \\
№ de grãos/vagem & 0,184 & 0,294 & 0,065 & 4,2 \\
PMG & 0,259 & 0,487 & 0,942 & 2,9 \\
Produtividade & 0,314 & 0,044 & 0,317 & 5,5
\end{tabular}

ICV: Índice de cobertura vegetal; PMG.: Peso de mil grãos; - : Sem efeito.

Observa-se que ocorreu um elevado índice pluviométrico durante a época de condução do experimento, em especial, durante as épocas de aplicação dos tratamentos herbicidas (Tabela 1 e Figura 1). Fator esse, aliado as condições do solo, que apresentavam pouca cobertura vegetal e área com declive, possivelmente ocorreu um escoamento superficial e/ou lixiviação dos herbicidas, que são importantes fatores na perda de herbicidas para águas superficiais e subterrâneas (INOUE et al. 2003).

Considerando que com o aumento da profundidade do perfil do solo, o teor de matéria orgânica reduz, e aliada a baixa capacidade de sorção da atrazina pela fração mineral, essas características tendem a aumentar o potencial de lixiviação do herbicida, pois ocorre uma redução dos compostos orgânicos do solo (MARTINAZZO et al. 2011), no qual a alta taxa pluviométrica associada as caraterísticas físicoquímicas dos herbicidas, contribuíram para ausência dos efeitos do herbicida sobre a soja. Um exemplo disso pode ser verificado no trabalho de BACHEGA et al. (2009) onde avaliaram que o herbicida sulfentrazone lixiviou até $10 \mathrm{~cm}$ de profundidade, mesmo com $106 \mathrm{~mm}$ de precipitação. Sendo assim, a 
lixiviação de cada produto é dependente de sua formulação, de sua composição e das características físicoquímicas, podendo ser mais ou menos afetado pela precipitação ocorrente logo após a aplicação.

Avaliando-se de forma isolada a estatura de planta para cada herbicida e para ambas as épocas, sendo assim, possível afirmar que a redução da estatura foi mais pronunciada quando houve a aplicação de atrazina isolada (Tabela 3).

Tabela 3. Estatura da soja em função da média de épocas de aplicação dos herbicidas atrazina e atrazina + simazina antes da semeadura.

Table 3. Soybean height according to the average times of application of the herbicides atrazine and atrazine + simazine before sowing.

\begin{tabular}{ccc}
\hline Herbicidas & Estatura (15 DAE) & Estatura (30 DAE) \\
\hline Atrazina & $9,25 \mathrm{~b}$ & $19,40 \mathrm{~b}$ \\
Atrazina+Simazina & $10,00 \mathrm{a}$ & $21,40 \mathrm{a}$ \\
\hline
\end{tabular}

Médias seguidas pela mesma letra na coluna não diferem significativamente entre si pelo teste de Tukey $(p<0,05)$.

Em relação a produtividade da soja, para ambos os herbicidas é possível afirmar que os efeitos esperados de redução de produtividade, uma vez que os herbicidas são indicados para o controle de plantas de folhas largas, não ocorreram, ficando assim mascarados. Outra vez esse efeito pode ter ocorrido em decorrência da alta precipitação que ocorreu logo após a aplicação dos tratamentos, cerca de $490 \mathrm{~mm}$ desde o início das aplicações de herbicida (56 DAS) até a semeadura da cultura (Tabela 1 e Figura 2). Os herbicidas do grupo das triazinas são relativamente persistentes na maioria dos solos (variando de um mês a dois anos) dependendo da formulação, da dose aplicada, bem como, das condições edafoclimáticas locais, possuem hidrólise lenta e alto potencial de escoamento superficial (VIDAL \& MEROTTO 2001). Os herbicidas atrazina e simazina possuem respectivamente solubilidade em água de 34,7 e $6,20 \mathrm{mg} \mathrm{L}^{-1}$, log Kow de 2,61 e 2,18, um pka de 1,60 e 1,62, e Koc de 100 e $97 \mathrm{~cm}^{3} \mathrm{~g}^{-1}$, respectivamente (INOUE et al. 2003, BARANOWSKA et al. 2008, PUBCHEM 2018). Em estudo realizado por INOUE et al. (2003), classificam a atrazina e a simazina através do índice de GUS, como lixiviadora e moderadamente a lixiviadoras respectivamente, índice este que aliado a pluviosidades ocorrida nos períodos pós aplicação, e juntamente as demais características já citadas, confirmam a hipótese de que possivelmente tenha ocorrido escorrimento superficial e por lixiviação.

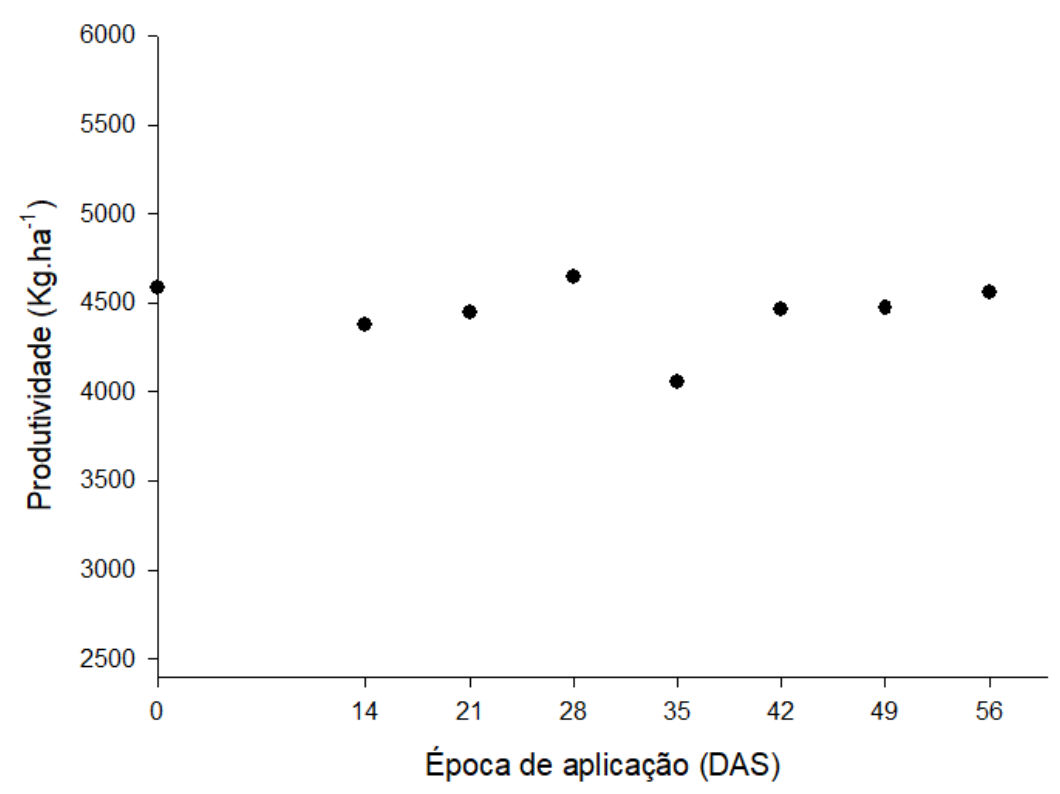

Figura 2. Produtividade da soja em função das épocas de aplicação de atrazina e atrazina + simazina em dias antes da semeadura (DAS).

Figure 2. Soybean yield as a function of times of application of atrazine and atrazine + simazine on days before sowing (DAS).

Em estudo realizado com quatro tipos diferentes de solos do Rio Grande do Sul, pode-se observar que o principal composto responsável pela sorção de atrazina ao solo é a matéria orgânica (DICK et al. 
2010). No entanto, embora o solo tenha apresentado $\mathrm{MO}$ de $3,2 \%$, a chuva foi o fator preponderante para a perda do herbicida por lixiviação e/ou escorrimento superficial. A atrazina pode percorrer até $0,5 \mathrm{~m}$ de profundidade em 60 dias após sua aplicação (CORREIA \& LANGENBACH 2006) fato este que corrobora com a afirmação que a atrazina possui um alto potencial de lixiviação.

\section{Experimento em casa de vegetação}

Não foi verificado interação entre herbicidas e dose, no entanto foram verificados efeitos simples para o fator herbicidas para as variáveis fitotoxicidade aos 21 e 28 DAE e efeito simples do fator dose para todas as variáveis analisadas (Tabela 4).

Tabela 4. Análise da variância (teste F) para as variáveis da soja em função da aplicação de doses de atrazina e atrazina + simazina.

Table 4. Analysis of the variance ( $F$ test) for the soybean variables as a function of the doses of atrazine and atrazine + simazine.

\begin{tabular}{lcccc}
\hline \multicolumn{1}{c}{ Variáveis } & Herbicida & Dose & Herbicida X Dose & CV (\%) \\
\hline Área Foliar & 0,607 & $<0,001$ & 0,984 & 31 \\
Diâmetro do caule & 0,352 & $<0,001$ & 0,607 & 16 \\
Estatura 07 DAE & 0,537 & 0,716 & 0,678 & 4 \\
Estatura 14 DAE & 0,243 & $<0,001$ & 0,320 & 15 \\
Estatura 21 DAE & 0,177 & $<0,001$ & 0,198 & 21 \\
Estatura 28 DAE & 0,591 & $<0,001$ & 0,737 & 25 \\
Fitotoxicidade 07DAE & 0,116 & $<0,001$ & 0,283 & 25 \\
Fitotoxicidade 14 DAE & 0,344 & $<0,001$ & 0,778 & 27 \\
Fitotoxicidade 21 DAE & 0,028 & $<0,001$ & 0,928 & 22 \\
Fitotoxicidade 28 DAE & 0,032 & $<0,001$ & 0,540 & 15 \\
Matéria seca & 0,769 & $<0,001$ & 0,931 & 15 \\
\hline
\end{tabular}

Avaliando-se a fitotoxicidade da soja em função de resíduos dos herbicidas atrazina e atrazina + simazina, observou-se que os resíduos de atrazina foram mais prejudiciais comparados com a mistura formulada (Tabela 5). Ambos herbicidas apresentavam a mesma quantidade de ingrediente ativo, sendo $500 \mathrm{~g}$ i.a. $\mathrm{L}^{-1}$ para atrazina e $500+500 \mathrm{~g}$ i.a. $\mathrm{L}^{-1}$ para atrazina + simazina. Resultados semelhantes foram observados por YU \& MCCULLOUGH (2016), os quais verificaram que atrazina causa maiores danos às plantas daninhas comparados com simazina. A atrazina e simazina possuem meia vida de 60 e 22 dias respectivamente (INOUE et al. 2003), fator que proporcionou com que a atrazina tivesse efeitos mais severos, pois a meia vida está diretamente ligada ao efeito do herbicida. Com o início do processo de germinação foram realizadas as avaliações de fitotoxicidade, inicialmente todas as plantas emergiram, mas com diferenças visuais de toxicidade, a qual sempre foi mais pronunciada quanto maior a dose do herbicida, iniciou-se por uma necrose ocorrida na borda do limbo foliar, ocasionando uma rápida necrose em toda a folha, e morte dos meristemas, ocasionado a senescência da planta nas maiores doses, quando comparada a testemunha, todos os tratamentos apresentaram uma estatura menor, mesmo para os tratamentos onde a fitotoxicidade foi baixa. A absorção dos herbicidas aplicados no solo pode ocorrer de diferentes formas, no caso de herbicidas sistêmicos, como a atrazina e simazina, são absorvidos pelo sistema radicular, onde são rapidamente translocados e distribuídos via xilema e acumulado nos meristemas da planta (BLANCO et al. 2013).

Os herbicidas pertencentes ao grupo químico das triazinas interrompem o fluxo de elétrons no fotossistema II, desencadeando um processo chamado de peroxidação lipídica, processo esse que ocorre quando a clorofila eleva-se a um estado enérgico elevado (Tripet), que resulta na formação e oxigênio singlet, o qual resultará em peroxidação lipídica na membrana plasmática, geralmente as plantas são mais sensíveis quão mais tenro é o tecido, com a necrose do tecido foliar ocorre a perda da capacidade fotossintética levando a planta a morte (OLIVEIRA JR et al. 2011). O residual no solo dos herbicidas do grupo das triazinas causou incrementos lineares na fitotoxicidade da soja, sendo que a cada $1000 \mathrm{~g} \mathrm{i.a.} \mathrm{ha}^{-1}$ a fitotoxicidade na soja aumentou cerca de 27\% (Figura 3A). Em estudo realizado com a aplicação de atrazina em pós-emergência da soja, mostrou que o aumento da dose do herbicida, propiciou um aumento na mortalidade da cultura, no qual, doses superiores a $800 \mathrm{~g}$ i.a. ha ${ }^{-1}$ obtiveram controle em plantas de soja 
acima de $80 \%$ aos 30 dias após a aplicação do herbicida (GRIGOLLI et al. 2017). Sendo assim, o efeito visual de fitotoxicidade fica mais pronunciado com o aumento da dose e a evolução nas avaliações.

Tabela 5. Valores médios de fitotoxicidade para os diferentes herbicidas aplicados.

Table 5. Average phytotoxicity values for the different herbicides applied.

\begin{tabular}{ccc}
\hline Herbicidas & Fitotoxicidade (21 DAE) & Fitotoxicidade (28 DAE) \\
\hline Atrazina & $47,3 \mathrm{~B}$ & $55,0 \mathrm{~B}$ \\
Atrazina+Simazina & $38,9 \mathrm{~A}$ & $46,3 \mathrm{~A}$ \\
\hline
\end{tabular}

Médias seguidas pela mesma letra na coluna não diferem significativamente entre si pelo teste de Tukey $(p<0,05)$.
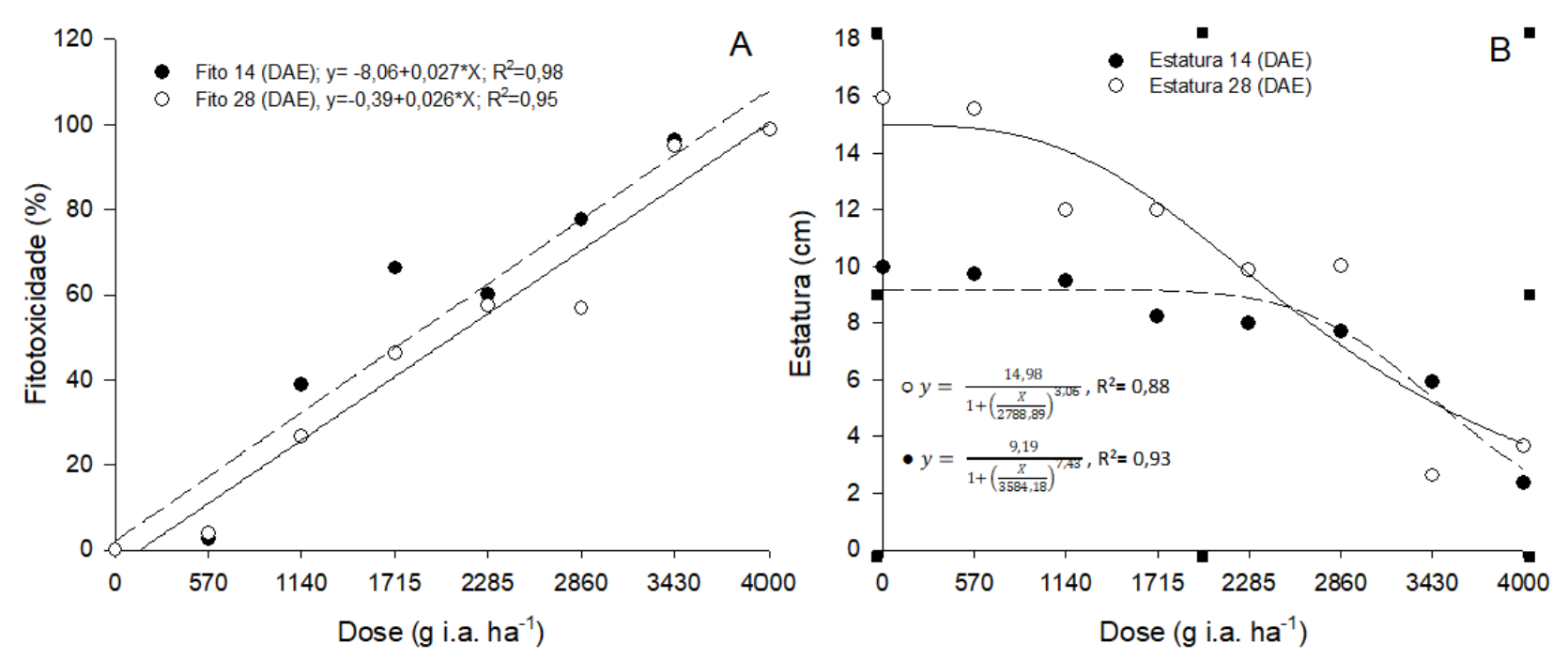

Figura 3. Fitotoxicidade (A) e estatura $(B)$ da soja cultivada em solo com resíduo de atrazina e atrazina + simazina.

Figure 3. Phytotoxicity $(A)$ and height $(B)$ of soybean cultivated in soil with atrazine and atrazine + simazine residue.

Notou-se que com o acréscimo da dose do herbicida, ocorre uma diminuição na estatura de plantas, onde a maior dose coincidiu com a menor estatura de planta, na qual a resposta ocorre de forma similar aos 14 e 28 DAE (Figura 3B). Aos 14 DAE, a estatura não é alterada até a dose de $2285 \mathrm{~g}$ i.a. ha ${ }^{-1}$, no entanto em doses superiores apresentaram uma rápida redução na estatura. Já aos $28 \mathrm{DAE}$, observa-se uma diminuição acentuada com a acréscimo das doses a partir da dose $570 \mathrm{~g}$ i.a. ha ${ }^{-1}$. Efeito este que está relacionado a persistência dos produtos no solo, e ao tempo de exposição da cultura ao herbicida, o qual, esses produtos podem permanecer no solo entre poucas semanas até dois anos, quando encontrarem condições de $\mathrm{pH}$ baixo e teores de matéria orgânica elevados, ficando fortemente adsorvido por coloides orgânicos e minerais e influenciados pelo $\mathrm{pH}$, de maneira geral para a atrazina, solos com maior quantidade de matéria orgânica costumam resultar em maior sorção de alguns herbicidas, dentre eles a atrazina (KASOZI et al. 2012). O pH do solo afeta diretamente a sorção da atrazina devido a seu efeito direto nas cargas elétricas da matéria orgânica do solo, das argilas e do próprio herbicida (INOUE et al. 2003).

A atrazina por sua vez é uma base fraca (pKa $\sim 1,7$ ), e encontra-se na forma neutra em ambientes com valores elevados de pH (MUDHOO \& GARG 2011). Solos com pH elevado, usualmente apresentam uma capacidade de troca de cátions (CTC), mais elevada, o que acarreta na diminuição das cargas positivas do herbicida. A maior capacidade de sorção está presente na fração argila do solo devido a apresentarem cargas líquidas negativas. No entanto, a superfície das argilas pode apresentar valores de $\mathrm{pH}$ menores ( 0,5 a 4,0 unidades) do que o pH da solução do solo, o que possivelmente aumenta a sorção da atrazina por estas frações minerais em condições de pH baixo (VONBERG et al. 2014).

A translocação de atrazina nas plantas ocorre pelo xilema, em que o gradiente de transpiração acelera o processo de absorção no solo. Os maiores danos nas culturas ocorrem quando a planta aumenta a taxa de transpiração, ocorrendo assim maiores taxas de absorção do herbicida (OLIVEIRA JR et al. 2011).

$O$ incremento das doses dos herbicidas causou uma redução linear na matéria seca da soja (Figura 
$4 A$ ), sendo que esse comportamento é similar aos observados na fitotoxicidade. A dose que reduz $50 \%$ da matéria seca da soja foi $1835 \mathrm{~g}$ i.a. ha ${ }^{-1}$, sendo que na maior dose aplicada dos herbicidas a redução foi de 95,53\% em comparação a testemunha. Fato este que ocorreu em trabalho realizado com a cultura da cenoura, onde a massa seca da parte aérea avaliada aos 29 DAA foi reduzida em $60 \%$ para maior dose de atrazina (250 g i.a.ha ${ }^{-1}$ ) (FURLAN et al. 2016). Sendo correspondente as avaliações visuais de fitotoxicidade, onde ambos os herbicidas avaliados não diferiram entre si, o que ocorre devido a quantidade de produto absorvido e translocado aumentar à medida que a dose aumenta.
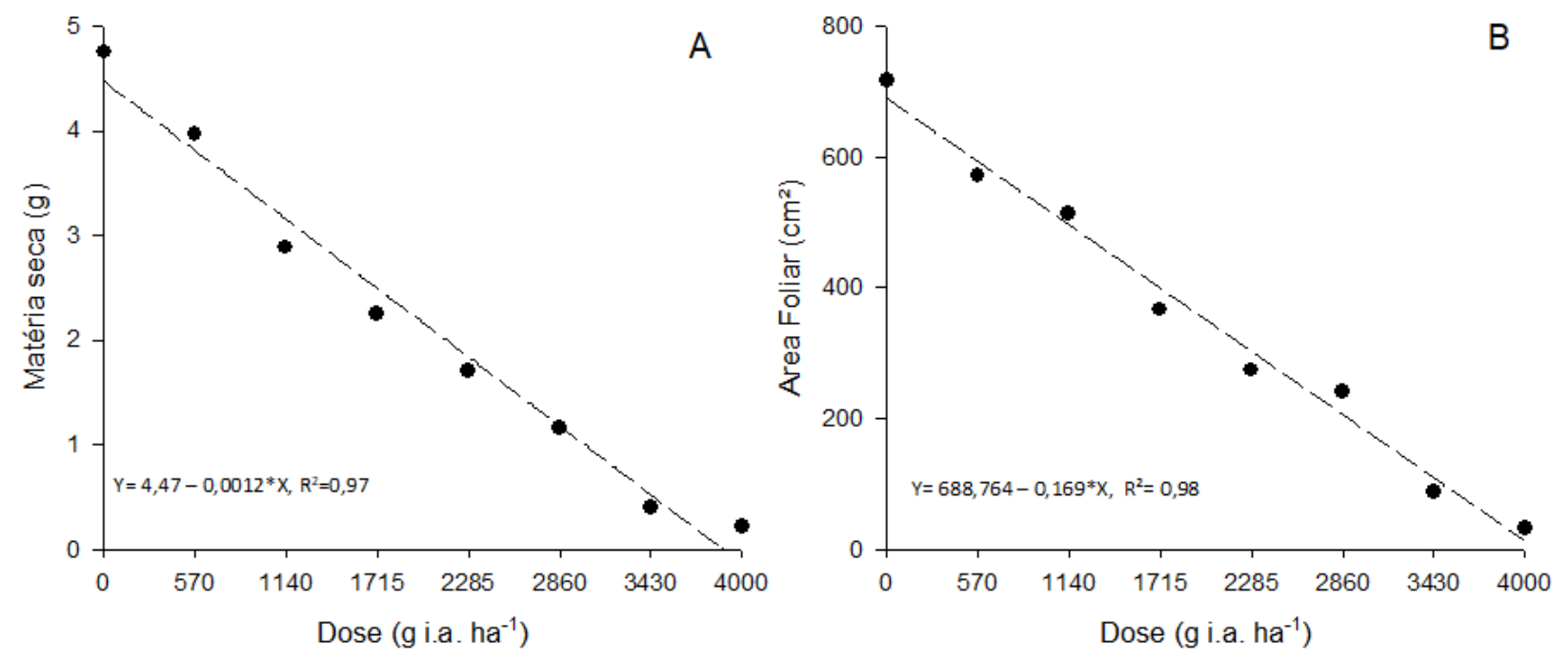

Figura 4. Matéria seca $(A)$ e área foliar $(B)$ da soja cultivada em solo com resíduo de atrazina e atrazina + simazina.

Figure 4. Dry matter $(A)$ and leaf area $(B)$ of soybean cultivated in soil with atrazine and atrazine + simazine residue.

Os resultados da área foliar foram semelhantes aos observados para as variáveis fitotoxicidade e matéria seca das plantas de soja, uma vez que a redução foi linear ao aumento das doses dos herbicidas, na qual a dose de $1951 \mathrm{~g}$ i.a.ha ${ }^{-1}$ reduziu em $50 \%$ a área foliar e a maior dose reduziu em $95,5 \%$ em comparação a testemunha (Figura 4B). Sendo assim, quanto maior a fitotoxicidade das plantas, menor será a área foliar, que por sua vez, conduzirá na redução do acúmulo de matéria seca.

Nota-se a importância de observar o período residual de herbicidas, cujo tenham efeito sobre culturas em sucessão, sendo que a durabilidade do residual dos herbicidas pode ser alterado, principalmente por precipitação, bem como temperatura, precipitação e características físico-químicas do solo. Como o regime de chuva foi alto nos intervalos entre as épocas de aplicações de herbicidas e a semeadura da soja, os sintomas das triazinas não foram observadas na cultura. No entanto, é de fundamental importância, respeitar um período seguro entre a aplicação dos herbicidas e a semeadura da soja em condições de baixa pluviosidade no período para que não haja efeito deletérios, uma vez que baixas doses podem causar danos significativos ao desenvolvimento da soja em condições de baixa dissipação dos herbicidas do grupo das triazinas (Figuras 3 e 4).

\section{CONCLUSÃO}

Não há efeito residual dos herbicidas do grupo das triazinas na cultura da soja quando estes são aplicados antes da semeadura em ambientes de alta pluviosidade.

Aplicações de atrazina e atrazina + simazina em condições de baixa precipitação, causa intoxicação na cultura mesmo nas menores doses.

\section{REFERÊNCIAS}

BACHEGA TF et al. 2009. Lixiviação de sulfentrazone e amicarbazone em colunas de solo com adição de óleo mineral. Planta Daninha 27: 363-370.

BARANOWSKA I et al. 2008. ELISA and HPLC methods for atrazine and simazine determination in trophic chains samples. Ecotoxicology and Environmental Safety 70: 341-348.

BLANCO FMG et al. 2013. Herbicide-soil interactions applied to maize crop under Brazilian conditions. In: PRICE A. (Ed.). Herbicides - Current research and case studies in use. London: Intech. p.47-73. 
CORREIA FV \& LANGENBACH T. 2006. Dinâmica da distribuição e degradação de atrazina em argissolo vermelhoamarelo sob condições de clima tropical úmido. Revista Brasileira Ciência do Solo 30: 183-192.

DICK DP et al. 2010. Matéria orgânica em quatro tipos de solos brasileiros: composição química e sorção de atrazina. Química Nova 3: 14-19.

EMBRAPA. 2013. Empresa Brasileira de Pesquisa Agropecuária. Sistema Brasileiro de Classificação de Solos. 3.ed. Brasília: Embrapa. 353p.

FURLAN RG et al. 2016. Simulação do efeito residual da atrazina em cenoura. Horticultura Brasileira 34: $584-587$.

GRIGOLLI JFJ et al. 2017. Controle de plantas de soja e supressão do capim em milho consorciado com Brachiaria ruziziensis. Arquivos do Instituto Biológico 84: 1-7.

INMET. 2018. Instituto Nacional de Meteorologia. Estações Automáticas/ Consulta Dados da Estação Automática: Frederico Westphalen (RS). Disponível em: http://www.inmet.gov.br. Acesso em: 11 mar. 2018.

INOUE MH et al. 2003. Critérios para avaliação do potencial de lixiviação dos herbicidas comercializados no estado do Paraná. Planta Daninha 21: 313-323.

KASOZI GN et al. 2012. Sorption of atrazine and ametryn by carbonatic and non-carbonatic soils of varied origin. Environmental Pollution 169: 12-19.

MANCUSO MAC et al. 2011. Efeito residual de herbicidas no solo (“Carryover"). Revista Brasileira de Herbicidas 10: 151-164.

MARTINAZZO R et al. 2011. Sorção de atrazina e mesotriona em latossolos e estimativa potencial de contaminação. Revista Química Nova 34: 1378-1384.

MUDHOO A \& GARG VK. 2011. Sorption, transport and transformation of atrazine in soils, minerals and composts. Pedosphere 21: 11-25.

OLIVEIRA JR RS et al. 2011. Biologia e manejo de plantas daninhas. 1.ed. Curitiba: Omnipax. 348p.

PUBCHEM. 2018. Open Chemistry Database. Atrazine. Disponível em: https://pubchem.ncbi.nlm.nih.gov/compound/atrazine\#section=Top. Acesso em: 23 abr. 2018.

SANTOS DP et al. 2013. Determination of bioindicators of auxinic herbicides residues. Revista Ceres 60: 354-362.

SBCPD. 1995. Sociedade Brasileira da Ciência das Plantas Daninhas. Procedimentos para instalação, avaliação e análise de experimentos com herbicidas. Londrina: SBCPD. 42p.

VIDAL RA \& MEROTTO JR A. 2001. Herbicidologia. Porto Alegre: Evangraf. 152p.

VONBERG $D$ et al. 2014. Atrazine soil core residue analysis from an agricultural field 21 years after its ban. Journal of Environmental Quality 43: 1450-1459.

YU J \& MCCULLOUGH PE. 2016. Efficacy and Fate of Atrazine and Simazine in Doveweed (Murdannia nudiflora) Weed Science 64: 379-388. 